\title{
Eysenck Personality Questionnaire Revised-Abbreviated for Informal Caregivers
}

\author{
Fernando L. Vázquez ${ }^{1 *}$, Patricia Otero², Lara López ${ }^{1}$, Vanessa Blanco ${ }^{3}$, María José \\ Ferraces ${ }^{4}$ y Ángela Torres ${ }^{5}$
}

'Departamento de Psicología Clínica y Psicobiología, Universidad de Santiago de Compostela, '2Departamento de Psicología, Universidad de A Coruña, ${ }^{3}$ Departamento de Psicología Evolutiva y de la Educación, Universidad de Santiago de Compostela, ${ }^{4}$ Departamento de Psicología Social, Básica y Metodología, Universidad de Santiago de Compostela, ${ }^{5}$ Departamento de Psiquiatría, Radiología, Salud Pública, Enfermería y Medicina, Universidad de Santiago de Compostela

- Received: 03 - 07 - 2018 . Accepted: 03 - 04 - 2019 . Avaliable online: 03 - 05 - 2019

ABSTRACT: The objective of this study was to analyze the psychometric properties of the Spanish version of the Eysenck Personality Questionnaire Revised-Abbreviated (EPQR-A) in informal caregivers. Trained, independent evaluators administered the EPQR-A and evaluated informal caregivers' depressive symptoms, automatic negative thoughts, self-efficacy, and pleasant social contacts, and clinical experts assessed major depressive episode in 592 caregivers (87.2\% women, mean age 55.4 years). Women scored significantly higher on Neuroticism than men $(p<.001)$. Subscale internal consistencies were .77 for Neuroticism, .75 for Extraversion, .47 for Sincerity; and .24 for Psychoticism. These four factors accounted for 38.1\% of total variance. However, a three-factor model (excluding Psychoticism) better fit the data. Neuroticism was significantly, inversely correlated with both self-efficacy $(r=-.35)$ and pleasant social contacts $(r=$ -.22), and positively correlated with both depressive symptoms $(r=.59)$ and negative thoughts $(r=.53)$. Extraversion was significantly, inversely correlated with both depressive symptoms $(r=-.22)$ and negative thoughts $(r=-.22)$, and positively correlated with both selfefficacy $(r=.36)$ and pleasant social contacts $(r=.16)$. A cutoff score of 4 on Neuroticism suitably discriminated between depressed and non-depressed informal caregivers (sensitivity $=68.1 \%$, specificity $=79.9 \%$ ).

KEYWORDS: EPQR-A, Personality, Caregiver, Psychometric properties.

\section{Cuestionario de Personalidad de Eysenck Revisado-Abreviado para cuidadores informales}

ABSTRACT: El objetivo de este estudio fue analizar las propiedades psicométricas de la versión española del Eysenck Personality Questionnaire Revised-Abbreviated (EPQR-A) en cuidadores informales. Evaluadores independientes entrenados administraron el EPQR-A y evaluaron la sintomatología depresiva, pensamientos automáticos negativos, autoeficacia y contactos sociales agradables y clínicos expertos valoraron el diagnóstico de episodio depresivo mayor a 592 cuidadores (87.2\% mujeres, media de edad 55.4 años). Las mujeres obtuvieron una puntuación en Neuroticismo significativamente mayor que los hombres $(p<.001)$. La consistencia interna de las subescalas fue .77 en Neuroticismo, .75 en Extraversión, .47 en Sinceridad y .24 en Psicoticismo. Estos factores explicaron el $38.1 \%$ de la varianza. Pero un modelo de tres factores (excluyendo Psicoticismo) ajustó mejor con los datos. El Neuroticismo correlacionó significativa e inversamente con autoeficacia $(r=-.35)$ y contactos sociales $(r=-.22)$, y directamente con sintomatología depresiva $(r=$ .59) y pensamientos negativos $(r=.53)$. La Extraversión correlacionó significativa e inversamente con sintomatología depresiva $(r=-.22)$ y pensamientos negativos $(r=-.22)$, y directamente con autoeficacia $(r=.36)$ y contactos sociales $(r=.16)$. Un punto de corte de 4 en Neuroticismo discriminó adecuadamente entre cuidadores deprimidos y no deprimidos (sensibilidad $=68.1 \%$; especificidad $=79.9 \%$ ).

PALABRAS CLAVE: EPQR-A, Personalidad, Cuidador, Propiedades psicométricas.

*Correspondence: Fernando L. Vázquez.

Departamento de Psicología Clínica y Psicobiología, Universidad de Santiago de Compostela

CP: 15782, Santiago de Compostela, España.

E-mail: fernandolino.vazquez@usc.es

(C) 2019 Sociedad Universitaria de Investigación en Psicología y Salud. Publicado por Consejo General de Colegios Oficiales de Psicólogos, España. Este es un artículo Open Access bajo la CC BY-NC-ND licencia (http://creativecommons.org/licencias/by-nc-nd/4.0/).
One of the most solid theoretical and empirical models of personality was developed by Eysenck (1967, 1970, 1981), who described personality as based on three independent dimensions: Neuroticism, Extraversion and 
Psychoticism. The neuroticism / stability dimension refers to how easily and frequently a person becomes upset and anguished. Those who score high on this dimension tend to be anxious, depressed, tense, feel guilty; those who score low tend to be stable and emotionally balanced. The extraversion / introversion dimension refers to tendencies toward sociability, vivacity, activity, and dominance. Extraverted individuals are characterized as sociable, communicative, uninhibited, active, talkative and dominant; in contrast, introverted individuals are passive, quiet, reserved and reflective. The psychoticism / superego dimension implies a tendency towards psychological detachment from and a lack of concern for others. Those who score high are characterized as hostile, aggressive, impulsive, manipulative, suspicious, egocentric, cold and impersonal; those who score low tend to be altruistic, empathetic, solicitous, cooperative and warm.

The evaluation tools derived from this theoretical model are the 90-item Eysenck Personality Questionnaire (Eysenck \& Eysenck, 1975) and, later, the 100-item Revised Eysenck Personality Questionnaire (EPQR) (Eysenck, Eysenck, \& Barret, 1985). However, the practical disadvantages of these questionnaires' lengths for research and clinical practice have led to the development of shorter forms: the 48-item Short Form of the Revised Eysenck Personality Questionnaire (EPQR-S, Eysenck et al., 1985) and the 24-item Eysenck Personality Questionnaire Revised-Abbreviated (EPQR-A; Francis, Brown, \& Philipchalk, 1992). The EPQR-A was validated in a sample of 685 university students in England, Canada and Australia. The Neuroticism, Extraversion and Sincerity subscales showed adequate psychometric properties, with satisfactory internal consistency indices $(\alpha=.70-.77, \alpha=.74-.84$, and $\alpha=$ $.59-.65$, respectively) and high correlations with the analogous long version (EPQR) subscales. However, the Psychoticism subscale had a lower internal consistency index ( $\alpha=$.33-.52) and low correlation coefficient with its EQPR analogue.

Versions have been translated into Hebrew (Katz \& Francis, 2000), French (Lewis, Francis, Shevlin, \& Forrest, 2002) and Spanish (Sandín, Valiente, Chorot, Olmedo, \& Santed, 2002).
Specifically, the factor structure of the Spanish version of the EPQR-A (Sandín, Valiente, Chorot et al., 2002) examined in a sample of 263 university students showed a four-factor structure (Extraversion, Neuroticism, Psychoticism and Sincerity). However, its psychometric properties had some limitations. Extraversion, Neuroticism and Sincerity all had adequate internal consistency ( $\alpha=.74, \alpha=.78$, and $\alpha=.54$, respectively) and factorial validity, but Psychoticism had low internal consistency $(\alpha=.63)$ and questionable factorial validity (Sandín, Valiente, Olmedo, Chorot, \& Santed, 2002).

To date, the EPQR-A has been validated mainly in student samples (e.g, Katz \& Francis 2000; Lewis et al., 2002; Sandín, Valiente, Chorot et al., 2002; Shevlin, Bailey, \& Adamson, 2002). As far as we know, no study has evaluated its reliability and validity with informal caregivers, despite its potential usefulness in this population. Although it is well known that psychopathological disorders are frequent in caregivers (Torres et al., 2015, Pinquart \& Söresen, 2003), variability in the emotional response to care suggests that individual variables operate on the perception of the care situation and coping strategies. In recent years, there has been increased interest in assessing the influence of personality traits on different mental health indicators among caregivers. Specifically, using the Big Five Personality Questionnaire (Costa \& McCrae, 1992), it has been found that neuroticism and extraversion are positively and negatively associated, respectively, with caregiver depression, burden and distress (Melo, Maroco, \& de Mendoça, 2011 ). Consequently, evaluation of caregiver personality would allow us to identify those with greater vulnerability for developing a mental disorder and to adapt treatment to the caregiver's individual characteristics. Furthermore, the reduced number of EPQR-A items is especially useful when surveying caregivers, because they have limited time due to task overload, are older (average age $\sim 50$ years) and have medium-tolow education (Otero et al., 2015), which make it difficult for them to respond to a long battery of questionnaires.

Given the importance of assessing personality in informal caregivers and the 
lack of research validating the EPQR-A in this population, the objective of this study was to analyze the psychometric properties and factorial structure of the Spanish version of EPQR-A in a sample of informal caregivers.

\section{METHODS}

\section{- PARTICIPANTS}

The study sample was drawn from the informal caregiver population of Galicia, a $29,434 \mathrm{~km}^{2}$ region in the northwest of Spain with a population of $2,732,347$. Participants were selected through a simple random sampling of the official registry of caregivers of the Ministry of Labor and Welfare of that region. To participate, subjects had to: (a) be the primary informal caregiver of an officially recognized dependent, (b) live in the same house as the cared person, (c) provide informed consent. We excluded those who: (a) presented any communication difficulties (e.g. were unable to read or write) (b) had any condition that made evaluation impossible (e.g., mental retardation, significant cognitive impairment, severe visual impairment), or (c) had undergone psychological or pharmacological treatment in the last two months.

The response rate was 98.2\%. Of the 603 invited to participate, 11 did not adequately complete the EPQR-A and were eliminated from the analyses related to this instrument, leaving a final sample of 592 subjects $(87.2 \%$ women, mean age 55.4 years).

All participants were informed of the nature of the study and gave informed consent. Participation was voluntary, without financial compensation or incentive of any kind. The study was carried out according to the Declaration of Helsinki and was approved by the Bioethics Committee of the university where the study was conducted.

\section{-MEASURES}

Sociodemographic and care-related variables. Caregiver data were collected using a questionnaire developed for this study, including: gender, age, marital status, social class, educational level, and relationship with the person for whom they provided care. We also collected information about the person who received their care, including: gender, age, and diagnoses. In addition, the number of years the caregiver had been caring for the dependent and the number of daily hours dedicated to this care were collected.

Eysenck Personality Questionnaire RevisedAbreviated (EPQR-A; Francis et al., 1992; Spanish version of Sandín, Valiente, Chorot, et al., 2002). This 24-item self-report questionnaire includes four subscales of six items each with dichotomous (yes / no) response options. Three subscales measure Neuroticism, Extraversion and Psychoticism, while a fourth (Sincerity; called "Lie Scale" in the English version) evaluates the tendency to provide socially desired responses. Scores on each subscale range from 0 to 6 and a higher score indicates greater presence of that trait. Internal consistencies (Cronbach's $\alpha$ ) are .78 for Neuroticism, .74 for Extraversion, .63 for Psychoticism, and .54 for Sincerity.

Center for Epidemiological Studies Depression Scale (CES-D; Radloff, 1977; Spanish version of Vázquez, Blanco, \& López, 2007). This 20 -item self-report scale provides a continuous score reflecting level of depressive symptoms during the last week. Each item is evaluated on a four-point Likert scale from 0 (rarely or never) to 3 (most of the time). Scores range from 0 to 60 and a higher score corresponds to greater depressive symptoms. Internal consistency is .89.

The Structured Clinical Interview for DSM5® - Clinician Version (SCID-5-CV; First, Williams, Karg, \& Spitzer, 2015). This semistructured interview provides DSM-5 diagnoses and must be administered by a clinician. It includes the most common disorders in clinical practice: depressive disorder, bipolar disorder, schizophrenia and other psychotic disorders, substance use disorders, anxiety disorders, obsessive-compulsive disorder, posttraumatic stress disorder, attention deficit hyperactivity disorder, and adaptive disorders, as well as screening for 17 additional disorders. We used the module corresponding to major depressive episodes. Inter-rater reliability $(\kappa)$ ranges from .70 to 1.00 .

Automatic Thoughts Questionnaire (ATQ-N; Hollon \& Kendall, 1980; Spanish version of 
Otero, Vázquez, Blanco, \& Torres, 2017). This 30-item self-report questionnaire evaluates the frequency of negative automatic thoughts during the prior week on a five-point Likert scale from 1 (never) to 5 (always). Total score ranges from 30 to 150 and a higher score indicates higher frequency of negative thoughts. Internal consistency is .96 .

Generalized Self-Efficacy Scale (GSES; Schwarzer \& Jerusalem, 1995; Spanish version of Baessler \& Schwarzer, 1996). This 10-item self-report scale assesses the feeling of personal competence to effectively handle stressful situations. Each item is evaluated on a four-point Likert scale ranging from 1 (not at all true) to 4 (completely true). Scores range from 10 to 40, with a higher score indicating a greater sense of self-efficacy. The scale has a high internal consistency $(\alpha=.87)$ and considerable predictive validity (Sanjuán, Pérez, \& Bermúdez, 2000).

Registration of pleasant social contacts. This ad hoc self-report questionnaire evaluates the number of pleasant social contacts (in person or over the phone) that participants maintained during the past seven days.

\section{-PROCEDURE}

Caregivers were invited via letter to participate in the study and asked to return a sealed postcard if they did not wish to do so. Those who did not return the card were contacted and a brief description of the study was provided. Those with continued interest were invited to participate in the evaluation, in two parts: first, completing the questionnaires and second, major depression episode diagnosis evaluation. In the first part, three psychologists collected sociodemographic and care situation information and subsequently delivered the self-administered questionnaires (EPQR-A, CES-D, ATQ-N, GSES and the registration of pleasant social contacts). The evaluators were previously trained by an expert in clinical psychology evaluation during two 90-minute sessions that included lectures and roleplay. A subsequent pilot test was conducted, in which each interviewer practiced their skills with five caregivers with similar characteristics to the study participants. These tests were recorded to refine the interview and evaluate the adherence to the evaluation protocol. Feedback was provided to each interviewer until they could adequately collect information.

In the second part of the evaluation, two diagnostic clinicians, each with more than 20 years of experience, established the suitability of the diagnosis of major depressive episode for each caregiver, using the SCID-5 during an approximately 70 -minute assessment. Clinicians who participated in the diagnostic process were blinded to the results from the first part of the evaluation.

\section{- DATA ANALYSIS}

We used SPSS for Windows (version 22.0) and SPSS_Amos Graphics (version 22) for data analyses. For the total sample and for the two subsamples, frequencies, percentages, means and standard deviations were calculated to describe sociodemographic variables, care situation, EPQR-A items score, depressive symptoms, negative thoughts, general selfefficacy and pleasant social contacts score. Diagnosis of major depressive episode was also analyzed. Student's $t$-test for independent samples was calculated to test for significant gender differences on each EPQR-A subscale.

For the total sample, to analyze reliability, Pearson's correlations were calculated between the scores on each of the items and the total corrected score (i.e., the total score without that item). We also calculated Cronbach's alpha for each EPQR-A subscale to analyze internal consistency.

To analyze the factor structure of the EPQR-A in the informal caregiver population, a cross-validation was performed. The total sample was subdivided into two groups by randomly selecting $50 \%$ of the cases. Next, an exploratory factor analysis (EFA) was conducted on the first subsample using principal components analysis. For extraction of the number of factors, we took into account the criteria used for the Spanish validation of the questionnaire (Sandín, Valiente, Chorot, et al., 2002) including: (a) the theoretical model underlying the EPQR-A, which suggests the existence of three personality factors and one sincerity factor, (b) evidence from the literature on the consistency of the four dimensions, (c) Kaiser's 
criterion (retention of factors with eigenvalues above 1), (d) scree test (Cattell, 1966), and (e) interpretability criterion of the different possible factorial structures (Gorsuch, 1983). Subsequently, in a second phase, we conducted an orthogonal Varimax rotation to try to minimize the number of large-weight items in a factor. The measure of adequacy of the sample was performed using the Kaiser-Meyer-Olkin index and the identity correlation matrix was assessed using Bartlett's sphericity test. Subsequently, to assess the explanatory capacity of the EPQR-A, we performed two separate confirmatory factor analysis (CFAs) on the second subsample: a four-factor model (Neuroticism, Extraversion, Psychoticism, Sincerity) and a three-factor model (Neuroticism, Extraversion, Sincerity). The Maximum Likelihood method, which is most suitable for dichotomous data (Bollen, 1989), was used. We used the boostrap procedure to obtain two-tailed confidential intervals for standardized regression weights. The following adjustment indicators were obtained: (a) the $\chi^{2}$ statistic, which reports the distance between the sample and hypothetical variance / covariance matrix. Nonsignificance indicates a low discrepancy between the two matrices; however, since this statistic is highly sensitive to sample size (with $n \geq 200$ usually being significant) it is recommended that one take into account the degrees of freedom $\left(\chi^{2}\right.$ / $d f$ ) which are considered acceptable when they are less than 3; (b) the Goodness-of-Fit Index (GFI), for which a value $>0.90$ is considered a good fit; (c) the Comparative Fit Index (CFI), for which values between 0.90 and 0.95 indicate good model fit; (d) the Root Mean Square Error of Approximation (RMSEA), which reports the difference between the population correlation matrix and that proposed in the sample model, and (e) the Standardized Root Mean Square Residual (SRMR), which reports the standardized residuals. For the later two indices, values $<.08$ indicate good model fit.

For the overall sample, to study the convergent and discriminant validity of the Neuroticism and Extraversion subscales, we calculated Pearson's correlation with depressive symptoms, negative thoughts, self-efficacy and social contacts. In addition, to evaluate the concurrent validity of the Neuroticism subscale, we calculated Student's t-test for independent samples and conducted a discriminant classification analysis for the diagnosis of major depressive episode. Finally, we identified cutpoints that differentiate between non-depressed and depressed subjects through the ROC (Receiver-Operating Characteristics) curve analysis.

The effect sizes for difference of means (d) and correlation $(r)$ were calculated. An effect size of $d=0.2-0.5$ or $r=0.1$ is interpreted as small, $d=0.5-0.8$ or $r=0.3$ as medium and $d \geq$ 0.8 or $r=0.5$ as large (Cohen, 1988, 1992). Given that the interpretation of effect sizes (i.e., small, medium, large) is not uniform within or between contexts, we calculated the associated percentile and the percentage of smaller effect sizes out of the total possible effect sizes (see Vilariño, Amado, Vázquez, \& Arce, 2018). For the conversion of the sizes, we referred to the tables in Salgado (2018).

\section{RESULTS}

\section{-SAMPLE PROFILE AND PERSONALITY DIMENSIONS}

Our sample was $87.2 \%$ women. Their mean age was 55.4 years (SD $=11.9), 72.1 \%$ had a partner, and $53.9 \%$ had completed primary education. The mean score for depressive symptoms was $18.2(S D=11.4$ ) and $15.9 \%$ of caregivers were diagnosed with major depressive episode. The mean scores for negative thoughts, self-efficacy and social contacts were 49.7 (SD = 21.0), $29.5(S D=6.3)$ and 23.1 ( $S D=17.0)$, respectively. Table 1 shows the participants' sociodemographic characteristics for the total sample, and the two subsamples, as well as information about the care situation and clinical variables. There were no significant differences between the mean scores for sociodemographic and care-related characteristics, depressive scores, depressive episodes, negative thoughts, self-efficacy and social contacts between the two subsamples.

Regarding personality, average subscale scores were: Neuroticism $=3.01(S D=1.95)$, Extraversion $=3.65(S D=1.88)$, Psychoticism $=$ $1.26(S D=0.99)$, and Sincerity $=1.28(S D$ 
$=1.16)$. As shown in Table 2, males scored significantly lower than females on Neuroticism, for the overall sample, $+(590)=-5.30, p<$ $.001, d=0.65,95 \% \mathrm{Cl} 0.39-0.91$ (Percentile 67.72 , larger than $35.44 \%$ of all possible positive effect sizes), and for both subsamples [ + (312) $=-4.43, p<.001, d=0.74,95 \% \mathrm{Cl} 0.41$ 1.07 (Percentile 69.85 , larger than $39.70 \%$ of all possible positive effect sizes), and $t$ (52.442) $=-2.98, p=.004, d=0.43,95 \% \mathrm{Cl} 0.07$ 0.79 (Percentile 61.79, larger than $23.58 \%$ of all possible positive effect sizes), respectively]. There were no significant gender differences on any of the other subscales.

\section{-ANALYSIS OF RELIABILITY}

Table 3 shows the mean item and subscale scores, frequencies of scores, corrected elementtotal correlation for each item, subscale internal consistencies and mean inter-item correlation coefficient. Among participants' valid answers, $61.6 \%$ of items were scored 0 and $38.4 \%$ were scored 1. The mean of items ranged from 0.01 for item Would being in debt worry you? and Would you take drugs? to 0.79 for Are you rather lively? Corrected element-total correlation coefficients ranged from -.09 for Would being in debt worry you? to .32 for Do you offen feel fed-up? Mean

Table 1

Participant socio-demographic characteristics, care situation and clinical variables $(n=592)$

\begin{tabular}{|c|c|c|c|c|c|c|}
\hline \multirow[t]{2}{*}{ Variables } & \multicolumn{2}{|c|}{$\begin{array}{l}\text { Total sample } \\
\quad(n=592)\end{array}$} & \multicolumn{2}{|c|}{$\begin{array}{l}\text { First subsample } \\
\qquad(n=314)\end{array}$} & \multicolumn{2}{|c|}{$\begin{array}{l}\text { Second subsample } \\
\qquad(n=278)\end{array}$} \\
\hline & $n$ & $\%$ & $n$ & $\%$ & $n$ & $\%$ \\
\hline \multicolumn{7}{|l|}{ Gender } \\
\hline Men & 76 & 12.8 & 42 & 13.4 & 34 & 12.2 \\
\hline Women & 516 & 87.2 & 272 & 86.6 & 244 & 87.8 \\
\hline \multicolumn{7}{|l|}{ Age } \\
\hline Mean $(S D)$ & $55.4(11.9)$ & & $55.8(11.7)$ & & $55.0(12.1)$ & \\
\hline \multicolumn{7}{|l|}{ Marital status } \\
\hline Without partner & 165 & 27.9 & 96 & 30.6 & 69 & 24.8 \\
\hline With partner & 427 & 72.1 & 218 & 69.4 & 209 & 75.2 \\
\hline \multicolumn{7}{|l|}{ Social class } \\
\hline Low / Middle-low & 287 & 48.5 & 146 & 46.5 & 141 & 50.7 \\
\hline Middle / Middle-high & 305 & 51.5 & 168 & 53.5 & 137 & 49.3 \\
\hline Educational level & & & & & & \\
\hline Literate & 86 & 14.5 & 48 & 15.3 & 38 & 13.7 \\
\hline Primary & 319 & 53.9 & 162 & 51.6 & 157 & 56.4 \\
\hline Secondary / university & 187 & 31.6 & 104 & 33.1 & 83 & 29.9 \\
\hline \multicolumn{7}{|l|}{$\begin{array}{l}\text { Relationship to the } \\
\text { caregiver }\end{array}$} \\
\hline Father/mother & 221 & 37.3 & 124 & 39.5 & 97 & 34.9 \\
\hline Spouse & 67 & 11.3 & 38 & 12.1 & 29 & 10.4 \\
\hline Daughter/son & 171 & 28.9 & 80 & 25.5 & 91 & 32.8 \\
\hline Other relatives & 122 & 20.6 & 64 & 20.4 & 58 & 20.8 \\
\hline Other, non-relatives & 11 & 1.9 & 8 & 2.5 & 3 & 1.1 \\
\hline
\end{tabular}


Table 1 (Continuation)

Participant socio-demographic characteristics, care situation and clinical variables $(n=592)$

\begin{tabular}{|c|c|c|c|c|c|c|}
\hline \multirow[t]{2}{*}{ Variables } & \multicolumn{2}{|c|}{$\begin{array}{l}\text { Total sample } \\
\quad(n=592)\end{array}$} & \multicolumn{2}{|c|}{$\begin{array}{l}\text { First subsample } \\
\qquad(n=314)\end{array}$} & \multicolumn{2}{|c|}{$\begin{array}{l}\text { Second subsample } \\
\qquad(n=278)\end{array}$} \\
\hline & $n$ & $\%$ & $n$ & $\%$ & $n$ & $\%$ \\
\hline \multicolumn{7}{|l|}{$\begin{array}{l}\text { Disease of the person } \\
\text { cared }\end{array}$} \\
\hline Dementia & 178 & 30.1 & 98 & 31.2 & 80 & 28.8 \\
\hline $\begin{array}{l}\text { Mental and neurological } \\
\text { disorders, brain damage }\end{array}$ & 167 & 28.2 & 80 & 25.5 & 87 & 31.3 \\
\hline $\begin{array}{l}\text { Diseases of the } \\
\text { osteomuscular system, } \\
\text { connective tissue, } \\
\text { cardiovascular or } \\
\text { respiratory systems }\end{array}$ & 154 & 26.0 & 90 & 28.7 & 64 & 23.0 \\
\hline \multicolumn{7}{|l|}{$\begin{array}{l}\text { Gender of the person } \\
\text { cared }\end{array}$} \\
\hline Men & 220 & 37.2 & 122 & 38.9 & 98 & 35.3 \\
\hline Women & 372 & 62.8 & 192 & 61.1 & 180 & 64.7 \\
\hline Age of the person cared fo & & & & & & \\
\hline Mean $(S D)$ & $63.3(31.2)$ & & $65.4(30.3)$ & & $61.0(32.0)$ & \\
\hline Duration of care (years) & & & & & & \\
\hline Mean $(S D)$ & $13.2(9.4)$ & & $13.8(10.2)$ & & $12.6(8.4)$ & \\
\hline Daily hours devoted to care & & & & & & \\
\hline Mean $(S D)$ & $15.7(4.1)$ & & $15.8(4.0)$ & & $15.5(4.3)$ & \\
\hline Depressive symptoms & & & & & & \\
\hline Mean $(S D)$ & $18.2(11.4)$ & & $17.7(11.4)$ & & $18.8(11.3)$ & \\
\hline Major depressive episode & & & & & & \\
\hline Negative & 498 & 84.1 & 263 & 83.8 & 235 & 84.5 \\
\hline Positive & 94 & 15.9 & 51 & 16.2 & 43 & 15.5 \\
\hline Negative thoughts & & & & & & \\
\hline Mean $(S D)$ & $49.7(21.0)$ & & $48.6(20.3)$ & & $50.9(21.7)$ & \\
\hline General self-efficacy & & & & & & \\
\hline Mean $(S D)$ & $29.5(6.3)$ & & $29.7(6.3)$ & & $29.1(6.2)$ & \\
\hline Pleasant social contacts & & & & & & \\
\hline Mean $(S D)$ & $23.1(17.0)$ & & $23.8(17.5)$ & & $22.2(16.4)$ & \\
\hline
\end{tabular}


Table 2

Mean EPQR-A subscale scores by gender $(n=592)$

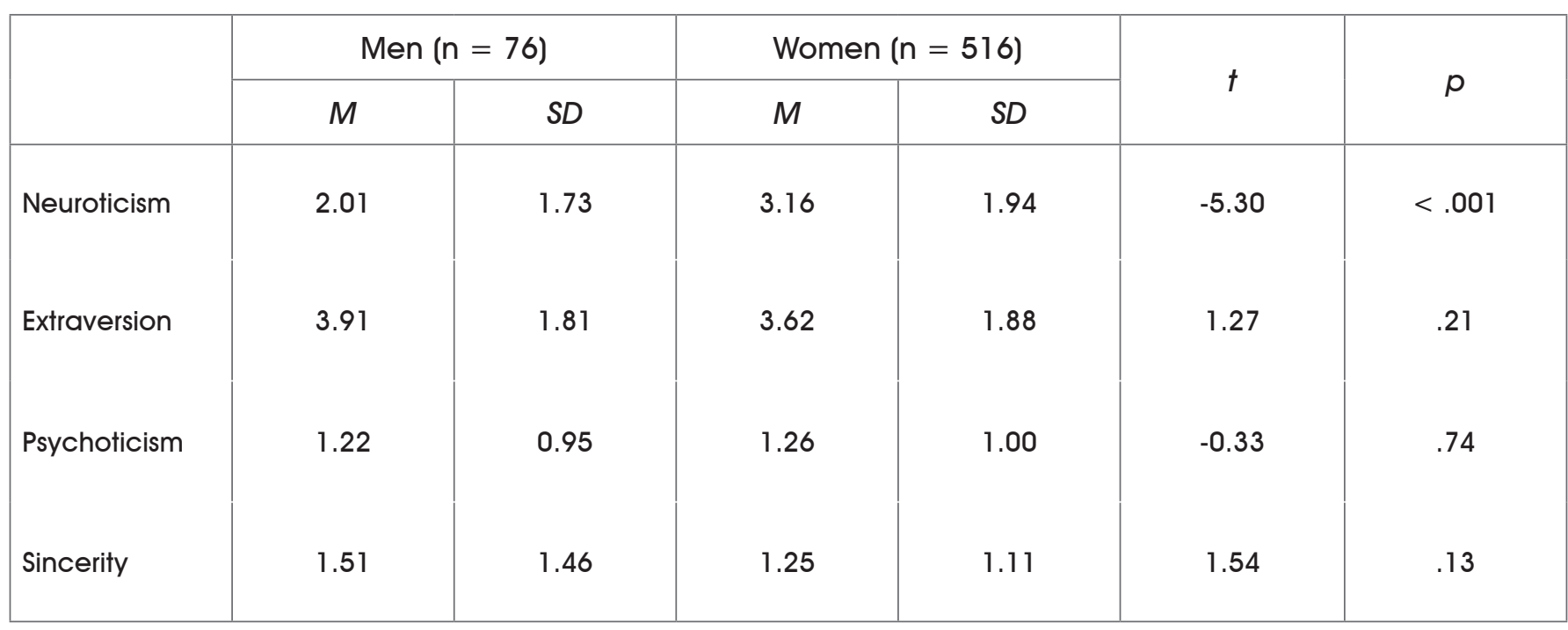

Table 3

Mean $(M)$ and standard deviations $(S D)$ of items and subscales, frequency of scores, the corrected element-total correlation $\left(r^{\text {tot }}\right)$ for each item and the internal consistency of subscales $(n=592)$

\begin{tabular}{|c|c|c|c|c|c|c|}
\hline \multirow{2}{*}{ Item (abbreviated) } & & \multirow{2}{*}{$M$} & \multirow{2}{*}{$S D$} & \multicolumn{2}{|c|}{ Score frequency $(\%)$} & \multirow{2}{*}{$r^{\text {tot }}$} \\
\hline & & & & Yes & No & \\
\hline 1. Moods go up and down? & $\mathrm{N}$ & 0.60 & 0.49 & 59.6 & 40.4 & .29 \\
\hline 2. Talkative person? & $\mathrm{E}$ & 0.76 & 0.43 & 76.4 & 23.6 & .21 \\
\hline 3. Debt worry you?* & $\mathrm{P}$ & 0.01 & 0.11 & 98.8 & 1.2 & -.09 \\
\hline 4. Are you rather lively? & $\mathrm{E}$ & 0.79 & 0.41 & 79.1 & 20.9 & .05 \\
\hline 5. Want to help yourself? & $S$ & 0.33 & 0.47 & 32.9 & 67.1 & .11 \\
\hline 6. Take drugs? & $\mathrm{P}$ & 0.01 & 0.10 & 1.0 & 99.0 & .02 \\
\hline 7. Blamed someone? & $\mathrm{S}$ & 0.06 & 0.23 & 5.6 & 94.4 & .12 \\
\hline 8. Go your own way? & $\mathrm{P}$ & 0.24 & 0.43 & 24.5 & 75.5 & .14 \\
\hline 9. Feel "fed-up"? & $\mathrm{N}$ & 0.46 & 0.50 & 45.8 & 54.2 & .32 \\
\hline $\begin{array}{l}\text { 10. Taken something from someone } \\
\text { else? }\end{array}$ & $\mathrm{S}$ & 0.12 & 0.33 & 12.3 & 87.7 & .10 \\
\hline $\begin{array}{l}11 . \text { Would you call yourself a } \\
\text { nervous person? }\end{array}$ & $\mathrm{N}$ & 0.59 & 0.49 & 59.0 & 41.0 & .25 \\
\hline $\begin{array}{l}\text { 12. Do you think marriage is old- } \\
\text { fashioned? }\end{array}$ & $\mathrm{P}$ & 0.10 & 0.30 & 10.3 & 89.7 & .11 \\
\hline $\begin{array}{l}\text { 13. Could you get life into a dull } \\
\text { party? }\end{array}$ & $E$ & 0.46 & 0.50 & 46.5 & 53.5 & .13 \\
\hline 14. Are you a worrier? & $\mathrm{N}$ & 0.72 & 0.45 & 72.0 & 28.0 & .23 \\
\hline
\end{tabular}




\section{Table 3 (Continuation)}

Mean $(M)$ and standard deviations (SD) of items and subscales, frequency of scores, the corrected element-total correlation $\left(r^{\text {tot }}\right)$ for each item and the internal consistency of subscales $(n=592)$

\begin{tabular}{|c|c|c|c|c|c|c|}
\hline \multirow{2}{*}{ Item (abbreviated) } & & \multirow{2}{*}{ M } & \multirow{2}{*}{$S D$} & \multicolumn{2}{|c|}{ Score frequency $(\%)$} & \multirow{2}{*}{$r^{\text {tot }}$} \\
\hline & & & & Yes & No & \\
\hline 15. Do you tend to keep in the background? & $\mathrm{E}$ & 0.41 & 0.49 & 58.8 & 41.2 & .16 \\
\hline $\begin{array}{l}\text { 16. Does it worry you if you know there are } \\
\text { mistakes in your work?*}\end{array}$ & $P$ & 0.42 & 0.49 & 41.9 & 58.1 & .06 \\
\hline 17. Have you ever cheated at a game? & $S$ & 0.16 & 0.37 & 16.4 & 83.6 & .14 \\
\hline 18. Do you suffer from "nerves"? & $\mathrm{N}$ & 0.31 & 0.46 & 30.7 & 69.3 & .27 \\
\hline 19. Have you ever taken advantage of someone? & $S$ & 0.06 & 0.24 & 6.3 & 93.8 & .14 \\
\hline 20. Are you mostly quiet? & $\mathrm{E}$ & 0.59 & 0.49 & 41.0 & 59.0 & .12 \\
\hline 21. Do you often feel lonely? & $\mathrm{N}$ & 0.34 & 0.48 & 34.1 & 65.9 & .19 \\
\hline 22. Is it better to follow the rules? & $\mathrm{P}$ & 0.47 & 0.50 & 53.0 & 47.0 & .07 \\
\hline $\begin{array}{l}\text { 23. Do other people think of you as being very } \\
\text { lively? }\end{array}$ & $\mathrm{E}$ & 0.63 & 0.48 & 63.3 & 36.7 & .17 \\
\hline 24. Do you always practice what you preach? & $S$ & 0.55 & 0.50 & 45.4 & 54.6 & .09 \\
\hline Neuroticism subscale & & 3.01 & 1.95 & & & \\
\hline Extraversion subscale & & 3.65 & 1.88 & & & \\
\hline Psychoticism subscale & & 1.26 & 0.99 & & & \\
\hline Sincerity subscale & & 1.28 & 1.16 & & & \\
\hline Neuroticism Cronbach's $\alpha$ & & & & & & .77 \\
\hline Extraversion Cronbach's $\alpha$ & & & & & & .75 \\
\hline Psychoticism Cronbach's $\alpha$ & & & & & & .24 \\
\hline Sincerity Cronbach's $\alpha$ & & & & & & .47 \\
\hline Mean inter-item correlation coeficient & & & & & & .039 \\
\hline
\end{tabular}


inter-item correlation coefficient was .039 (ranged from -.23 to .51).

Cronbach's alpha was .77 for Neuroticism, .75 for Extraversion, .24 for Psychoticism, and .47 for Sincerity.

\section{-ANALYSIS OF VALIDITY}

\section{Validity of construct}

The sample was divided into two halves using random selection of $50 \%$ of the sample. With the first half of the sample, an EFA was executed and with the second half, two CFAs were performed. Regarding the exploratory analysis, the KaiserMeyer-Olkin test of sample adequacy (KMO = $0.73)$ and Bartlett's sphericity index $\left(\chi^{2}(276)=\right.$ $1277.510 ; p<.001)$ indicated a good fit of the data for such analysis. We obtained nine factors with eigenvalues greater than 1, which explained $61.3 \%$ of the total variance. However, application of the Scree test, as in the Spanish validation (Sandín, Valiente, Chorot, et al., 2002), suggested three or four factors. As proposed by the empirical and theoretical criteria, we extracted four factors, which explained $38.1 \%$ of the total variance. The first factor explained $15.0 \%$ of the total variance and it included 6 items related to neuroticism, all with saturations $\geq .6$ (items 1, 9, 11, 14, 18 and 21 ). The second factor explained $9.1 \%$ of the variance and it included 6 items related to extraversion, including an item with a factorial weight between .5 and .6 (item 15) and five with factorial weights $\geq .6$ (items 2, 4, 13, 20 and 23). Third, the sincerity factor explained $8.3 \%$ of the variance and included 6 items: two with factorial weights between .3 and .4 (items 7 and 24) and three with factorial weights $\geq .6$ (items 10, 17 and 19); the factorial weight of item 5 did not reach the minimum value (.3). The last factor, related to psychoticism, explained $5.7 \%$ of the variance and included 6 items (items 3, 6, 8, 12, 16 and 22). This dimension is poorly defined by the data, since the factorial weights of items 3,6 and 16 do not reach the minimum value (.3) and their low communality values reflect that the factorial model hardly explains their variance. Table 4 shows the factorial weights and communalities of all the items.

With the second half of the sample, two CFAs were conducted: one based on a theoretical model with four factors and another with three factors (excluding Psychoticism). The CFA supported the correlated three-factor model (Neuroticism, Extraversion and Sincerity) of the EPQR-A. The overall fit was reasonable, and the fit index values were acceptable: $\chi^{2}(132)=245.119, p<$. $001 ; \chi^{2} / d f=1.857 ; \mathrm{GFI}=0.91 ; \mathrm{CFI}=0.86$; RMSEA $=0.056$ (95\% Cl 0.045-0.066); SRMR = 0.012 . The items had significant factorial weights, ranging between .26 in item 5 to .72 in item 23; although the weights for items 5, 7 and 24 were low (see Figure 1). The individual factor items for each factor were as follows: Neuroticism: six items ranging from .51 to $.68(M=.58)$; Extraversion: six items ranging from .47 to $.72(M=.59)$; and Sincerity: six items ranging from .26 to .58 (M $=.39$ ). The correlation between three EPQR-A factors indicates a significant negative relationship between Neuroticism and Extraversion $(r=-.25$, $p=.003)$, which yielded a small effect size.

Table 4

Factorial weights of EPQR-A items $(n=314)$

\begin{tabular}{|c|c|c|c|c|c|}
\hline Item & $\mathrm{N}$ & $E$ & S & $P$ & $\mathrm{H}^{2}$ \\
\hline \multicolumn{6}{|l|}{ Neuroticism } \\
\hline Does your mood often go up and down? (1) & .72 & & & & .54 \\
\hline Would you call yourself a nervous person? (11) & .70 & & & & .51 \\
\hline Are you a worrier? (14) & .69 & & & & .49 \\
\hline Do you suffer from "nerves"? (18) & .68 & & & & .46 \\
\hline Do you often feel "fed-up"? (9) & .63 & & & & .47 \\
\hline Do you often feel lonely? (21) & .61 & & & & .46 \\
\hline
\end{tabular}


Table 4 (Continuation)

Factorial weights of EPQR-A items $(n=314)$

\begin{tabular}{|c|c|c|c|c|c|}
\hline Item & $\mathrm{N}$ & $\mathrm{E}$ & $S$ & $\mathrm{P}$ & $\mathrm{H}^{2}$ \\
\hline \multicolumn{6}{|l|}{ Extraversion } \\
\hline Are you a talkative person? (2) & & .74 & & & .58 \\
\hline Do other people think of you as being very lively? (23) & & .70 & & & .55 \\
\hline Are you rather lively? (4) & & .67 & & & .49 \\
\hline Can you easily get some life into a rather dull party? (13) & & .65 & & & .50 \\
\hline Are you mostly quiet when you are with other people? (20) & & .60 & & & .51 \\
\hline $\begin{array}{l}\text { Do you tend to keep in the background on social occasions? } \\
\text { (15) }\end{array}$ & & .55 & & & .40 \\
\hline \multicolumn{6}{|l|}{ Sincerity } \\
\hline $\begin{array}{l}\text { Have you ever taken anything (even a pin or button) that } \\
\text { belonged to someone else? (10) }\end{array}$ & & & .75 & & .57 \\
\hline Have you ever cheated at a game? (17) & & & .68 & & .46 \\
\hline Have you ever taken advantage of someone? (19) & & & .61 & & .39 \\
\hline $\begin{array}{l}\text { Have you ever blamed someone for doing something you } \\
\text { knew was really your fault? (7) }\end{array}$ & & & .37 & & .19 \\
\hline Do you always practice what you preach? (24) & & & .31 & & .18 \\
\hline $\begin{array}{l}\text { Were you ever greedy by helping yourself to more than your } \\
\text { share of anything? (5) }\end{array}$ & & & .26 & & .13 \\
\hline \multicolumn{6}{|l|}{ Psychoticism } \\
\hline $\begin{array}{l}\text { Do you prefer to go your own way rather than act by the } \\
\text { rules? (8) }\end{array}$ & & & & .70 & .53 \\
\hline $\begin{array}{l}\text { Do you think that marriage is old-fashioned and should be } \\
\text { done away with?(12) }\end{array}$ & & & & .57 & .32 \\
\hline Is it better to follow society's rules than make your own? (22) & & & & .48 & .24 \\
\hline $\begin{array}{l}\text { Does it worry you if you know there are mistakes in your work? } \\
(16)^{\star}\end{array}$ & & & & .26 & .08 \\
\hline $\begin{array}{l}\text { Would you take drugs which may have strange or dangerous } \\
\text { effects? (6) }\end{array}$ & & & & -.14 & .06 \\
\hline Would being in debt worry you? (3)* & & & & -.04 & .04 \\
\hline
\end{tabular}

Note. The number of the ítem is indicated in parenthesis. $\mathrm{N}=$ Neuroticism; $\mathrm{E}=$ Extraversion; $\mathrm{P}=\mathrm{Psychoticism;} \mathrm{S}=$ Sincerity; $\mathrm{H}^{2}=$ communality. ${ }^{*}$ Items 3 and 16 were modified by the authors in the Spanish version.

Convergent-discriminant validity:

Neuroticism and Extraversion

We found significant inverse correlations between Neuroticism and self-efficacy $(r=-.35, p$ $<.001)$, and pleasant social contacts $(r=-.22, p$ $<.001$ ), but significant positive correlations with depressive symptoms $(r=.59, p<.001)$ and negative thoughts $(r=.53, p<.001)$.
Regarding Extraversion, we found significant inverse correlations with depressive symptoms $(r=$ $-.22, p<.001)$ and negative thoughts $(r=-.22$, $p<.001$ ), but significant positive correlations with self-efficacy $(r=.36, p<.001)$ and with pleasant social contacts $(r=.16, p<.001)$. The effect sizes, ranging from small to large, and the corresponding percentiles for the convergentdiscriminant validity are shown in Table 5. 


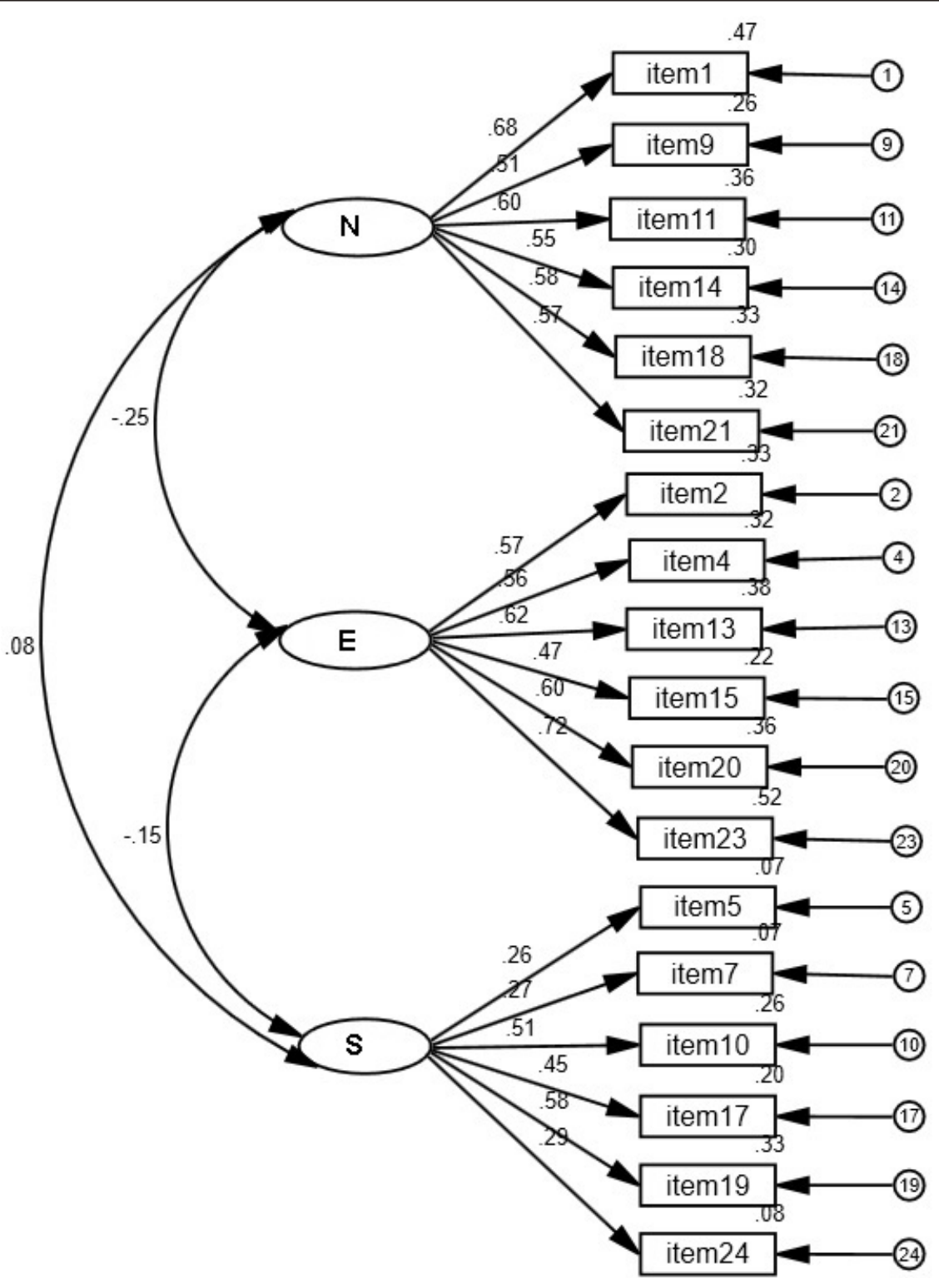

Figure 7. Results of the confirmatory factor analysis

Note. $\mathrm{N}=$ Neuroticism; $\mathrm{E}=$ Extraversion; $\mathrm{S}=$ Sincerity.

Predictive Validity: Neuroticism and Depression

Student's t-test showed that depressed caregivers had a significantly higher degree of Neuroticism compared to those who were nondepressed $(M=4.86$ vs. $M=2.66),+(590)$ $=14.75, p<.001, d=1.24,95 \% \mathrm{Cl} 1.01$ 1.47 (large effect size; see Table 5 for the corresponding percentile). Using a discriminant classification analysis, Wilks lambda was 0.83 , $\chi^{2}(1, N=592)=110.19, p<.001$. The canonical correlation, which measures the degree of association between discriminant scores and group membership, was .41. This analysis correctly classified $87.2 \%$ of depressed caregivers and $64.3 \%$ of non-depressed caregivers. Overall, $67.9 \%$ of all cases were correctly classified. The area under the ROC curve was .83 $(95 \% \mathrm{Cl} .79-.86)$, confirming that the EPQR-A Neuroticism subscale is useful for discriminating between caregivers with and without depression (see Figure 2). Using cutoff of 4 , the test had a sensitivity of $68.1 \%$ and specificity of $79.9 \%$, with $78.0 \%$ of cases correctly classified, and positive and negative predictive values of $39.0 \%$ and $93.0 \%$, respectively (see Table 6). 


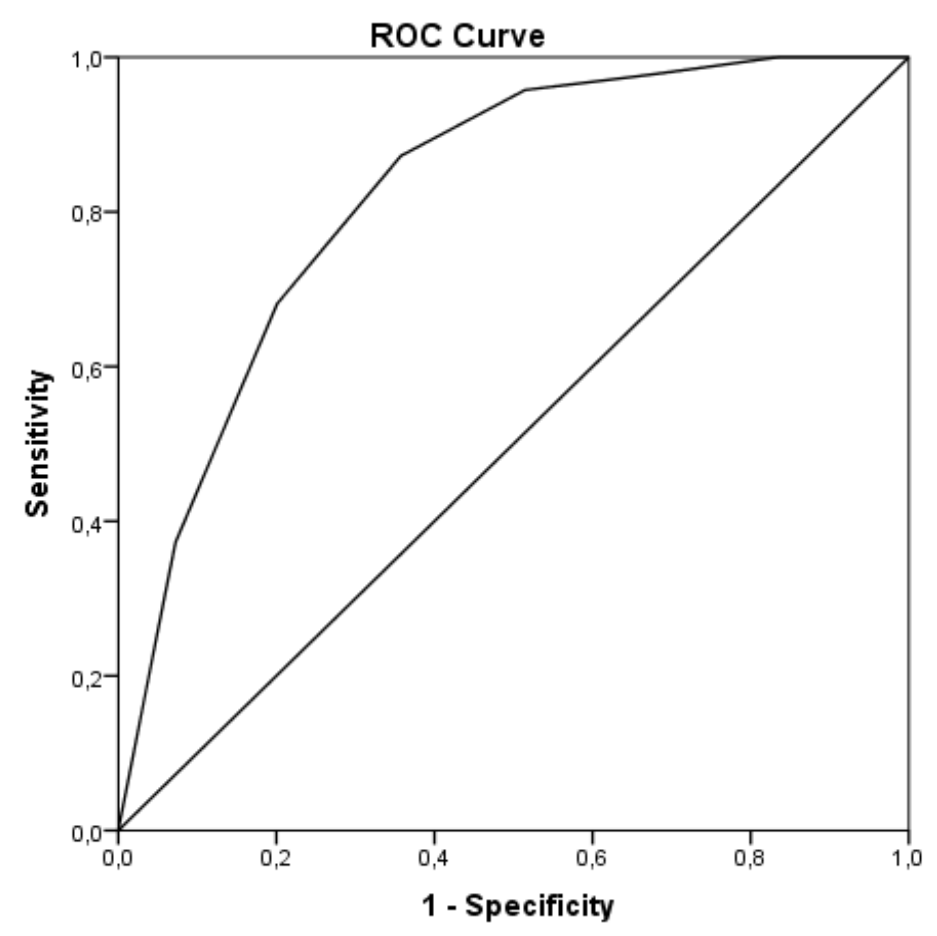

Figure 2. Receiver-Operating Characteristics (ROC) curve

Table 5

Effect sizes and their percentiles on the convergent-discriminant and predictive validity and predictive

\begin{tabular}{|c|c|c|c|c|}
\hline Validity/variables & $\begin{array}{c}r_{\text {person }} / \\
\text { Cohen's d }\end{array}$ & $\begin{array}{l}\text { Effect } \\
\text { size }\end{array}$ & $\begin{array}{l}\text { Percentile for } \\
\text { effect size }\end{array}$ & Interpretation \\
\hline \multicolumn{5}{|l|}{$\begin{array}{l}\text { Convergent-discriminant } \\
\text { validity }\end{array}$} \\
\hline \multicolumn{5}{|l|}{ Neuroticism } \\
\hline Depressive symptoms & .59 & Large & 84.85 & $\begin{array}{c}\text { Larger than } 69.70 \% \text { of all possible positive } \\
\text { effect sizes }\end{array}$ \\
\hline Negative thoughts & .53 & Large & 81.06 & $\begin{array}{c}\text { Larger than } 69.70 \% \text { of all possible positive } \\
\text { effect sizes }\end{array}$ \\
\hline Self-efficacy & -.35 & Medium & 70.19 & $\begin{array}{c}\text { Larger than } 40.38 \% \text { of all possible negative } \\
\text { effect sizes }\end{array}$ \\
\hline Pleasant social contacts & -.22 & Small & 62.55 & $\begin{array}{c}\text { Larger than } 25.10 \% \text { of all possible negative } \\
\text { effect sizes }\end{array}$ \\
\hline \multicolumn{5}{|l|}{ Extraversion } \\
\hline Depressive symptoms & -.22 & Small & 62.55 & $\begin{array}{c}\text { Larger than } 25.10 \% \text { of all possible negative } \\
\text { effect sizes }\end{array}$ \\
\hline Negative thoughts & -.22 & Small & 62.55 & $\begin{array}{c}\text { Larger than } 25.10 \% \text { of all possible negative } \\
\text { effect sizes }\end{array}$ \\
\hline Self-efficacy & .36 & Medium & 70.88 & $\begin{array}{c}\text { Larger than } 41.76 \% \text { of all possible positive } \\
\text { effect sizes }\end{array}$ \\
\hline Pleasant social contacts & .16 & Small & 59.10 & 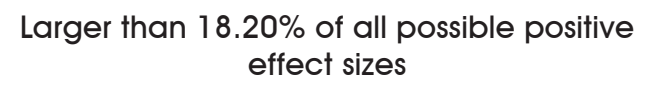 \\
\hline \multicolumn{5}{|l|}{ Predictive validity } \\
\hline Neuroticism & & & & \\
\hline Major depressive episode & 1.24 & Large & 81.06 & $\begin{array}{c}\text { Larger than } 62.12 \% \text { of all possible positive } \\
\text { effect sizes }\end{array}$ \\
\hline
\end{tabular}


Table 6

Measures of the diagnostic predictive capacity for the EPQR-A cut-off points

\begin{tabular}{|c|c|c|c|c|}
\hline Cut-off & Sensibility & Specificity & $\begin{array}{c}\text { Positive predictive } \\
\text { value }\end{array}$ & $\begin{array}{c}\text { Negative predictive } \\
\text { value }\end{array}$ \\
\hline 0 & 1.000 & .165 & .184 & 1.000 \\
1 & .978 & .317 & .213 & .987 \\
2 & .957 & .486 & .260 & .984 \\
3 & .872 & .643 & .315 & .964 \\
4 & .681 & .799 & .390 & .930 \\
5 & .372 & .928 & .493 & .887 \\
6 & .000 & 1.000 & 1.000 & .841 \\
\hline
\end{tabular}

\section{DISCUSSION}

The objective of this study was to analyze the psychometric properties of the Spanish version of the EPQR-A (Sandín, Valiente, Chorot, et al., 2002) in informal caregivers. As far as we know, this is the first study specifically aimed at examining it in this population. For three of the fourEPQR-A subscales, we obtained mean scores (3.01 in Neuroticism, 3.65 in Extraversion and 1.26 in Psychoticism) similar to those reported in the original questionnaire (Francis et al., 1992) and in the Spanish version (Sandín, Valiente, Chorot, et al., 2002). However, in our sample, the mean score for Sincerity (1.28) was lower than in the other two studies. Regarding gender, we found that women scored significantly higher than men in Neuroticism with a moderate effect size, which is consistent with other studies (Francis, 1993; Forrest, Lewis, \& Shevlin, 2000) and with Eysenck's (1967) theory on the biological basis of personality differences. It is also possible, that these differences are due to the differential socialization of the genders, in which women's education is more emotionally focused.

For internal consistency, we found acceptable alpha coefficients on Neuroticism and Extraversion ( $\alpha=.77$ and $\alpha=.75$, respectively), which is consistent to the original questionnaire $(\alpha$ $=.70-.77$ and $.74-.84)$ and the Spanish version $(\alpha=.78$ and .74$)$. In relation to Psychoticism, internal consistency was low $(\alpha=.24)$, in line with the original and Spanish versions, although it was lower than either the original questionnaire $(\alpha=.33-.52)$ or the Spanish version $(\alpha=.63)$. Due to the nature of the scale, most individuals get extremely low scores on Psychoticism, which might have been accentuated in the sample of this study. Because the sample was composed of informal caregivers, the empathy-altruism hypothesis may apply. That is, people with higher levels of empathy (the opposite of psychoticism) are more willing to help a family member suffering a health chronic condition (Trujillo Perrin, Elnasseh, Pierce, \& Mickens, 2016). Finally, internal consistency for Sincerity was $\alpha=.47$, slightly lower than in the original questionnaire $(\alpha=.59-.65)$ or the Spanish version $(\alpha=.54)$. A possible explanation is that in the present study motivation to seek social desirability was low, unlike other contexts (e.g., selection of staff).

The exploratory factor analysis showed the existence of four factors (Neuroticism, Extraversion, Psychoticism and Sincerity) that explained $38.1 \%$ of total variance. This factor structure is consistent with that found in the original questionnaire and in the Spanish version, and the contents of these factors are consistent with the theoretical model of personality proposed by Eysenck (1981). In our study, all EPQR-A items had high factor weights for the corresponding latent factors, except three items in Psychoticism and one in Sincerity that did not reach a satisfactory factor weight $(>.3)$; this finding is consistent with the Spanish version 
of EPQR-A. The results of the confirmatory factor analysis showed acceptable, albeit moderate, model fit for the three-factor model (excluding Psychoticism). This structure is not consistent with some previous studies which have found evidence for the unidimensionality of the four EPQR-A subscales (Forrest et al., 2000, Lewis et al., 2002, Shevlin et al., 2002). However, it is consistent with previous findings on psychometric deficiencies of the Psychoticism scale (Block, 1977; Eysenck et al., 1985, Forrest et al., 2000) and low factor loadings for some items (Forrest et al., 2000; Lewis et al., 2002). In addition, there was a significant inverse correlation between Neuroticism and Extraversion. These results are partially consistent with the original (Shevlin et al., 2002) and French (Lewis et al., 2002) versions of the questionnaire. However, in those versions, they also found relations between Neuroticism and Sincerity and between Sincerity and Psychoticism (Lewis et al., 2002).

On the other hand, we found that caregivers with higher levels of neuroticism have less selfefficacy, fewer social contacts, more depressive symptoms, and more negative thoughts. Furthermore, caregivers with higher levels of extraversion had fewer depressive symptoms, fewer negative thoughts, greater self-efficacy, and more social contacts. These results indicate that the EPQR-A has adequate convergentdiscriminant validity. Similar results were found in the study by Sandín, Valiente, Olmedo et al. (2002) and are consistent with prior finding in the caregiver population using other personality scale (Melo et al., 2011).

Depressed caregivers had significantly higher scores for Neuroticism. Likewise, Neuroticism discriminated between depressed and non-depressed caregivers, adequately classifying $67.9 \%$ of cases. This indicates that this subscale also possesses adequate predictive validity and specificity for mood disorders. The cutoff point of 4 was adequate to discriminate between depressed and non-depressed caregivers when sensitivity and specificity were given equal importance.

These findings carry several implications for research and clinical practice. First, they provide information on the reliability and validity of $E P Q R-A$ in the caregiver population. In addition, a three-factor version of the EPQR-A with a better fit to the data is proposed, which resolves the psychometric deficiciences of the Psychoticism scale. Furthermore, the cutoff that discriminates caregivers with high levels of neuroticism and discriminate between depressed and nondepressed subjects is very useful for the detection of at-risk caregivers in this high depression prevalence population (Torres et al., 2015). The well-known theoretical model on which EPQR-A is based and its brevity allow a reliable and rapid measure of this construct, adjusting to the limited time available in caregivers.

However, this study has some limitations. First, personality information was not obtained from all subjects assessed, which could introduce non-response biases. However, the scope of this limitation is minimal because of the low percentage of questionnaires eliminated (1.8\%). Second, variable measurement was simultaneous, so the emotional state of the caregivers may have influenced their responses to EPQR-A. Nevertheless, the different temporal range of the measurement items for personality and symptomatology allows for control of this possible influence. Finally, we did not make repeated measurements to evaluate test-retest reliability.

\section{- Conflict of interest}

The authors declare no conflict of interest.

\section{- Funding}

This work was supported by the Ministry of Economy and Competitiveness of Spain [grant number 2012-PN162 (PSI201237396)].

\section{- Acknowledgments}

The authors wish to thank the Ministry of Labor and Welfare (Xunta de Galicia) for their support.

\section{REFERENCES}

Baessler, J., \& Schwarzer, R. (1996). Evaluation of self-efficacy: Spanish adaptation of the General Self-Efficacy Scale. Ansiedad y Estrés, 2, 1-8.

Block, J. (1977). The Eysencks and psychoticism. Journal of Abnormal Psychology, 86, 653-654. doi:10.1037/0021-843X.86.6.653. 
Bollen, K. A. (1989). Structural Equations with Latent Variables. New York: Wiley.

Cattell, R. (1966). The Scree Test for the number of factors. Multivariate Behavioral Research, 1, 245-276. doi:10.1207/ s15327906mbr0102 10.

Cohen, J. (1988). Statistical power analysis for the behavioural sciences (2nd ed.). Hillsdale, New Jersey: Lawrence Erlbaum Associates.

Cohen, J. (1992). A power primer. Psychological Bulletin, 112, 155-159. doi:10.1037/00332909.112 .1 .155$.

Costa, P., \& McCrae, R. (1992). The NEO PI-R/ NEO-FFI Manual Supplement. Odessa: Psychological Assessments Resources.

Eysenck, H. J. (1967). The biological basis of personality. Springfield, IL: Charles C Thomas.

Eysenck, H. J. (1970). The structure of human personality $\left(3^{a}\right.$ ed.). London: Methuen.

Eysenck, H. J. (1981). A model for personality. Berlín: Springer-Verlag.

Eysenck, H. J., \& Eysenck, S. B. G. (1975). Manual of the Eysenck Personality Questionnaire. London: Hodder \& Stoughton.

Eysenck, S. B. G., Eysenck, H. J., \& Barrett, P. (1985). A revised version of the psychoticism scale. Personality and Individual Differences, 6, 21-29. doi:10.1016/0191-8869(85)900261.

First, M. B., Williams, J. B. W., Karg, R. S., \& Spitzer, R. L. (2015). Structured Clinical Interview for DSM-5 Disorders, Clinician Version (SCID5-CV). Arlington, VA: American Psychiatric Association.

Forrest, S., Lewis, C. A., \& Shevlin, M. (2000). Examining the factor structure and differential functioning of the Eysenck Personality Questionnaire Revised-Abbreviated. Personality and Individual Differences, 29, 579-588. doi:10.1016/S01918869(99)00220-2.

Francis, L. J. (1993). The dual nature of the Eysenckian neuroticism scales: A question of sex differences? Personality and Individual Differences, 15, 43-59. doi:10.1016/01918869(93)90040-A.

Francis, L. J., Brown, L. B., \& Philipchalk, R. (1992). The development of an abbreviated form of the Revised Eysenck Personality Questionnaire (EPQR-A): Its use among students in England, Canada, the U.S.A. and Australia. Personality and Individual Differences, 13, 443-449. doi:10.1016/0191-8869(92)90073-X.

Gorsuch, R. (1983). Factor analysis. Hillsdale, NJ: Erlbaum.

Hollon, S. D., \& Kendall, P. C. (1980). Cognitive self-statements in depression: Development of an Automatic Thoughts Questionnaire. Cognitive Therapy and Research, 4, 383-395. doi:10.1007/BF01178214.

Katz, Y. J., \& Francis, L. J. (2000). Hebrew Revised Eysenck Personality Questionnaire: Short Form (EPQR-S) and Abbreviated Form (EPQR-A). Social Behavior and Personality, 28, 555-560. doi:10.2224/sbp.2000.28.6.555.

Lewis, C. A., Francis, L. J., Shevlin, N., \& Forrest, S. (2002). Confirmatory factor analysis of the French translation of the Abbreviated form of the Revised Eysenck Personality Questionnaire (EPQR-A). European Journal of Psychological Assessment, 18, 179-185. doi:10.1027//10155759.18.2.179.

Melo, G., Maroco, J., \& de Mendoça, A. (2011). Influence of personality on caregiver's burden, depression and distress related to the BPSD. International Journal of Geriatric Psychiatry, 26, 1275-1282. doi:10.1002/gps.2677.

Otero, P., Smit, F., Cuijpers, P., Torres, A., Blanco, V., \& Vázquez, F. L. (2015). Long-term efficacy of indicated prevention of depression in nonprofessional caregivers: Randomized controlled trial. Psychological Medicine, 45, 1401-1412. doi:10.1017/S0033291714002505.

Otero, P., Vázquez, F. L., Blanco, V., \& Torres, A. (2017). Propiedades psicométricas del Cuestionario de Pensamientos Automáticos (ATQ) en la población de cuidadores familiares [Psychometric properties of the Automatic Thoughts Questionnaire (ATQ) in the family caregiver population]. Psicología Conductual Behavioral Psychology, 25, 387-403.

Pinquart, M., \& Sörensen, S. (2003). Differences between caregivers and noncaregivers in psychological health and physical health: A meta-analysis. Psychology and Aging, 18, 250267. doi:10.1037/0882-7974.18.2.250. 
Radloff, L. S. (1977). The CES-D Scale: A self-report depression scale for research in the general population. Applied Psychological Measurement, 1, 385-401. doi: $10.1177 / 014662167700100306$.

Salgado, J. F. (2018). Transforming the Area under the Normal Curve (AUC) into Cohen's d, Pearson's rpb, Odds-Ratio, and Natural Log Odds-Ratio: Two conversion tables. European Journal of Psychology Applied to Legal Context, 10, 35-47. doi:10.5093/eipalc2018a5.

Sandín, B., Valiente, R. M., Chorot, P., Olmedo, M., \& Santed, M. A. (2002). Versión española del cuestionario EPQR-Abreviado (EPQR-A) (I): análisis exploratorio de la estructura factorial [Spanish version of the Eysenck Personality Questionnaire-Revised (EPQR-A) (I): Exploratory factor analysis]. Revista de Psicopatología y Psicología Clínica, 7, 195-205. doi:10.5944/ rppc.vol.7.num.3.2002.3933.

Sandín, B., Valiente, R. M., Olmedo, M., Chorot, P., \& Santed, M. A. (2002). Versión española del cuestionario EQPR-Abreviado (EPQR-A) (II): replicación factorial, fiabilidad y validez [Spanish version of the Eysenck Personality QuestionnaireRevised (EPQR-A) (II): Factor analysis replication, reliability and validity]. Revista de Psicopatología y Psicología Clínica, 7, 207-216. doi:10.5944/ rppc.vol.7.num.3.2002.3934.

Sanjuán, P., Pérez, A. M., \& Bermúdez, J. (2000). Escala de Autoeficacia General: datos psicométricos de la adaptación para población española [The General Self-Efficacy Scale: Psychometric data from the Spanish adaptation]. Psicothema, 12, 509-513.
Schwarzer, R., \& Jerusalem, M. (1995). Generalized Self-Efficacy Scale. In J. Weinman, S. Wright, \&M. Johnston (Eds.) Measures in health psychology: A user's portfolio. Causal and control beliefs (pp. 35-37). Windsor: Nfer-Nelson.

Shevlin, M., Bailey, F., \& Adamson, G. (2002). Examining the factor structure and sources of differential functioning of the Eysenck Personality Questionnaire Revised-Abbreviated. Personality and Individual Differences, 32, 479-487. doi:10.1016/S0191-8869(01)00049-6.

Torres, A., Blanco, V., Vázquez, F. L., Díaz, O., Otero, P., \& Hermida, E. (2015). Prevalence of major depressive episodes in non-professional caregivers. Psychiatry Research, 226, 333-339. doi:10.1016/i.psychres.2014.12.066.

Trujillo, M. A., Perrin, P. B., Elnasseh, A., Pierce, B. S., \& Mickens, M. (2016). Personality traits in college students and caregiving for a relative with a chronic health condition. Journal of Aging Research, 9. doi: 10.1155/2016/3650927.

Vázquez, F. L., Blanco, V., \& López, M. (2007). An adaptation of the Center for Epidemiologic Studies Depression Scale for use in non-psychiatric Spanish populations. Psychiatry Research, 149, 247- 252. doi:10.1016/i.psychres.2006.03.004.

Vilariño, M., Amado, B. G., Vázquez, M. J., \& Arce, R. (2018). Psychological harm in women victims of intimate partner violence: Epidemiology and quantification of injury in mental health markers. Psychosocial Intervention, 27, 145-152. doi:10.5093/pi2018a23. 